\title{
The Parabolic Transform and Some Singular Integral Evolution Equations
}

\author{
Mahmoud M. El-Borai*, Khairia El-Said El-Nadi \\ Department of Mathematics and Computer Science, Faculty of Science, Alexandria University, Alexandria, Egypt
}

Received April 21, 2020; Revised June 6, 2020; Accepted June 12, 2020

Copyright $\bigcirc 2020$ by authors, all rights reserved. Authors agree that this article remains permanently open access under the terms of the Creative Commons Attribution License 4.0 International License

\begin{abstract}
Some singular integral evolution equations with wide class of closed operators are studied in Banach space. The considered integral equations are investigated without the existence of the resolvent of the closed operators. Also, some non-linear singular evolution equations are studied. An abstract parabolic transform is constructed to study the solutions of the considered ill-posed problems. Applications to fractional evolution equations and Hilfer fractional evolution equations are given. All the results can be applied to general singular integro-differential equations. The Fourier Transform plays an important role in constructing solutions of the Cauchy problems for parabolic and hyperbolic partial differential equations. This means that the Fourier transform is suitable but under conditions on the characteristic forms of the partial differential operators. Also, the Laplace transform plays an important role in studying the Cauchy problem for abstract differential equations in Banach space. But in this case, we need the existence of the resolvent of the considered abstract operators. This note is devoted to exploring the Cauchy problem for general singular integro-partial differential equations without conditions on the characteristic forms and also to study general singular integral evolution equations. Our approach is based on applying the new parabolic transform. This transform generalizes the methods developed within the regularization theory of ill-posed problems.
\end{abstract}

Keywords Abstract Parabolic Transform, Singular Integral Evolution Equations, Hilfer Fractional Differential Equations

AMS subject classifications: 34-K30, 26A33, 60H15, 47D60, 74D62, 35A05, 34G20.

\section{Introduction}

Let us consider the following singular evolution equations:

$$
\begin{gathered}
\mathrm{u}(\mathrm{t})=f(t)+\int_{0}^{t} \sum_{i=1}^{r} K_{i}(\mathrm{t}, \theta) \mathrm{A}_{i}(\theta) \mathrm{u}(\theta) \mathrm{d} \theta, \\
\mathrm{u}(\mathrm{t})=f(t)+\int_{0}^{t} \mathrm{~F}(V(\mathrm{t}, \theta)) \mathrm{d} \theta,
\end{gathered}
$$

Where $\left.\left\{A_{i}(\mathrm{t})\right\}: \mathrm{t} \in \mathrm{J}, \mathrm{i}=1,2, \ldots, \mathrm{r}\right\}$ is a family of linear closed operators defined on densely domains in a Banach space $\mathrm{E}, \mathrm{J}=[0, \mathrm{~T}]$ is an interval, $\mathrm{T}>0,\left\{\mathrm{~K}_{\mathrm{i}}(\mathrm{t}, \theta), \mathrm{t}, \theta \in \mathrm{J}, \theta\right.$ $<t\}$ is a family of linear bounded operated defined on $E$ to E, such that

$$
\left\|K_{i}(\mathrm{t}, \theta) \mathrm{h}\right\| \leq \frac{M}{(\mathrm{t}-\theta)^{1-\alpha}}\|h\|,
$$

For all $h \in \mathrm{E}, 0<\alpha \leq 1, \mathrm{M}$ is a positive constant independent on $t$ and $\theta,\|$.$\| is the norm in \mathrm{E}$,

$\mathrm{V}(\mathrm{t}, \theta)=\left(\mathrm{K}_{1}(\mathrm{t}, \theta) \mathrm{A}_{1}(\theta) \mathrm{u}(\theta), \ldots, \mathrm{K}_{\mathrm{r}}(\mathrm{t}, \theta) \mathrm{A}_{\mathrm{r}}(\theta) \mathrm{u}(\theta)\right), \mathrm{F}$ is an abstract function defined on $\mathrm{E}^{\mathrm{r}}$ to $\mathrm{E}$, for every $\mathrm{t}, \theta \in \mathrm{J}$, $\mathrm{t}>\theta, \mathrm{f}(\mathrm{t}) \in \mathrm{E}$ is a given continuous function in $\mathrm{t} \in \mathrm{J}$.

Let $D\left(A_{i}\right), i=1, \ldots, r$ be the domain of definitions of $A_{i}$. It is supposed that the domains $\mathrm{D}\left(\mathrm{A}_{1}\right), \ldots, \mathrm{D}\left(\mathrm{A}_{\mathrm{r}}\right)$ are independent of $\mathrm{t}$.

We assume that all the functions $A_{1}(t) h, \ldots, A_{r}(t) h$ are continuous on $\mathrm{J}$ for every $\mathrm{h} \in \cap_{i=1}^{r} \quad \mathrm{D}\left(A_{i}\right)$ and all the functions $K_{1}(t, \theta) h, \ldots, \operatorname{Kr}(t, \theta) h$ are continuous on $J \times J, t>$ $\theta$, for every $h \in E$.

It is assumed also that $\mathrm{F}$ satisfies the following Lipschitz condition;

$$
\left\|F(\eta)-\mathrm{F}\left(\eta^{*}\right)\right\| \leq \mathrm{M} \sum_{i=1}^{r}\left\|\eta_{i}-\eta_{i}^{*}\right\|,
$$

For all $\eta=\left(\eta_{1}, \ldots, \eta_{\mathrm{r}}\right), \eta^{*}=\left(\eta_{1}^{*}, \ldots, \eta_{\mathrm{r}}^{*}\right)$ in $\mathrm{E}^{\mathrm{r}}, \quad \mathrm{M}$ is a positive constant.

Equations (1.1) and (1.2) are studied for a wide class of the closed operators $A_{1}(t), \ldots, A_{r}(t)$. In general, these operators have no resolvents. This means that we shall study ill-posed problems. See [1-13]. 
In section 2, we shall define the abstract parabolic transform. Using this transform, we can find a dense set $S$ in $E$ such that if $f(t) \in S$, then equation (1.1) can be solved.

In section 3, we shall solve fractional integral evolution equations and Hilfer fractional integral evolution equations.

Also, some general singular integro-partial differential equations are studied. The properties of the solutions in all cases are given. In section 4, we shall study equation (1.2).

\section{Abstract Parabolic Transforms}

The parabolic transform is defined in [14]. Let us, now, try to modify the definition to be suitable for abstract integral equations. Let $\mathrm{Q}(\mathrm{t})$ be a strongly continuous semi-group defined on $\mathrm{E}$, with infinitesimal generator $\mathrm{B}$ defined on dense set $\mathrm{D}(\mathrm{B})$ in $\mathrm{E}$, such that $\mathrm{D}(\mathrm{B}) \subset$ $\cap_{i=1}^{r} \quad \mathrm{D}\left(A_{i}\right)$.

We assume that there exist constants, $\mathrm{M}$ and $\gamma, \mathrm{M}>0,0$ $<\gamma<\alpha$,

$$
\text { Such that: }\left\|A_{i}\left(t_{2}\right) Q\left(t_{1}\right) g\right\| \leq \frac{M}{t_{1}^{\gamma}}\|g\|,
$$

for all $\mathrm{i}=1, \ldots, \mathrm{r}$, and all $\mathrm{g} \in \mathrm{E}, \mathrm{t}_{1}, \mathrm{t}_{2} \in \mathrm{J}, \mathrm{t}_{1}>0$.

A parabolic transform of an abstract function $\varphi\left(t_{1}, \ldots, t_{\gamma}\right)$ is defined by

$\tilde{\varphi}\left(\mathrm{t}_{1}, \ldots, \mathrm{t} \gamma, c_{2}+c_{1} \mathrm{t}\right)=\mathrm{Q}\left(c_{2}+c_{1} \mathrm{t}\right) \varphi\left(\mathrm{t}_{1}, \ldots, \mathrm{t}_{\gamma}\right),(2.2)$

Where $c_{1}, c_{2}$ are constants, $c_{2}+c_{1} \mathrm{t} \geq 0, \mathrm{t}, \mathrm{t}_{\mathrm{i}} \in \mathrm{J}, \mathrm{i}=$ $1, \ldots, \gamma$, and $\varphi$ is an abstract function defined on $\mathrm{J}^{\mathrm{r}}$ with values in $\mathrm{E}$.

Let us study the following of singular integral evolution equation;

$$
v(\mathrm{t})=\tilde{f}(\mathrm{t}, \mathrm{ct})+\int_{0}^{t} \sum_{i=1}^{r} K_{i}(\mathrm{t}, \theta) \mathrm{A}_{i}(\theta) \tilde{v}(\theta, \mathrm{ct}-\mathrm{c} \theta) \mathrm{d} \theta,
$$

$\mathrm{c}$ is a positive number.

Theorem (2.1). Under conditions (1.3) and (2.1), there exists a unique solution $v(t) \in E$. This solution is continuous in $\mathrm{t} \in \mathrm{J}$.

Proof: Let us use the method of successive approximations.

Let $\left\{v_{\mathrm{n}}\right\}$ be a sequence defined by:

$$
v_{\mathrm{n}+1}(\mathrm{t})=\tilde{f}(\mathrm{t}, \mathrm{ct})+\int_{0}^{t} \sum_{i=1}^{r} K_{i}(\mathrm{t}, \theta) \mathrm{A}_{i}(\theta) \tilde{v}_{n}(\theta, \mathrm{ct}-c \theta) \mathrm{d} \theta
$$

The zero approximation $v_{0}(t)$ is chosen to be identically zero. Using conditions (1.3) and (2.1) and the properties of the operators $\mathrm{A}, \mathrm{K}, \mathrm{Q}$, it can be proved that the functions $v_{1}(t), \ldots, v_{n}(t), \ldots$ are continuous in $t \in J$ and with values in E.

Again, according to (1.3) and (2.1), we get

$\left\|v_{n+1(t)}-v_{n}(t)\right\| \leq \frac{M}{c^{\gamma}} \int_{0}^{t} \frac{\left\|v_{n}(\theta)-v_{n-1}(\theta)\right\|}{(t-\theta)^{1-\delta}} \mathrm{d} \theta$, where; $\delta=\alpha-\gamma$
Thus:

$$
\left\|v_{n+1}(t)-v_{n}(t)\right\| \leq \frac{M^{n+1}}{c^{n \gamma}} \frac{t^{n \delta}(\Gamma(\delta))^{n}}{\Gamma(n \delta+1)},
$$

Where $\Gamma($.$) is the gamma function. The last inequality$ leads to the fact that the sequence $\left\{v_{n}(t)\right\}$ uniformly converges in $\mathrm{E}$ to a continuous function $v(\mathrm{t})$ on $\mathrm{J}$, which represents the solution of equation (2.3). To prove the uniqueness, let us suppose that there are two solutions $v(t)$ and $v^{*}(t)$ of (2.3).

Thus;

$$
\left\|v(t)-v^{*}(t)\right\| \leq \mathrm{M} / \mathrm{c}^{v} \int_{0}^{t} \frac{\left\|v(\theta)-v^{*}(\theta)\right\|}{(t-\theta)^{1-\delta}} \mathrm{d} \theta
$$

By induction, one gets

$$
\left\|v(t)-v^{*}(t)\right\| \leq \frac{M^{n+1}}{c^{n \gamma}} \frac{t^{n \delta}(\Gamma(\delta))^{n}}{\Gamma(n \delta+1)}
$$

As $n \rightarrow \infty$, we get $v(t)=v^{*}(t)$

The following theorem proves that the solution $v(t)$ of equation (2.3) depends continuously on $\mathrm{f}(\mathrm{t})$

Theorem 2.2. Let $\varepsilon>0$. If $\|\mathrm{f}(\mathrm{t})\| \leq \varepsilon$, for all $\mathrm{t} \in \mathrm{J}$, then

$\|v(\mathrm{t})\| \leq \varepsilon \quad E_{\sigma}\left[\frac{\mathrm{M} \Gamma(\sigma) \mathrm{t}^{\sigma}}{C^{\sigma}}\right]$, Where; $\mathrm{E}_{\sigma}$ is the Mittag-Leffler function defined by $E_{\alpha}(t)=$ $\sum_{k=0}^{\infty} \frac{t^{k}}{\Gamma(k \alpha+1)}$,

Proof: If $\|\mathrm{f}(\mathrm{t})\| \leq \varepsilon$, we get

$$
\|v(t)\| \leq \varepsilon+\frac{M}{C^{\gamma}} \int_{0}^{t} \frac{\|v(\theta)\|}{(t-\theta)^{1-\sigma}} \mathrm{d} \theta,
$$

The last inequality leads to the required result.

Let us now try to discuss the ill-posed problem (1.1).

For this purpose, we need some of additional conditions. Suppose that for every $\mathrm{i}=1, \ldots, \mathrm{r}$ and every $t_{1}, t_{2}, t_{3} \in \mathrm{J}$, the operator $\mathrm{Q}\left(\mathrm{t}_{1}\right)$ commutes with $\mathrm{K}_{\mathrm{i}}\left(\mathrm{t}_{2}, \mathrm{t}_{3}\right)$ and commutes with $\mathrm{A}_{\mathrm{i}}\left(\mathrm{t}_{3}\right)$ :

$$
\mathrm{Q}\left(t_{1}\right) \mathrm{K}_{\mathrm{i}}\left(t_{2}, t_{3}\right) \mathrm{f}=\mathrm{K}_{\mathrm{i}}\left(t_{2}, t_{3}\right) \mathrm{Q}\left(t_{1}\right) \mathrm{f},
$$

For all $\mathrm{f} \in \mathrm{E}, t_{1}, t_{2}, t_{3} \in \mathrm{J}, t_{2}>t_{3}$, and

$$
\mathrm{Q}\left(t_{1}\right) \mathrm{A}_{\mathrm{i}}\left(t_{3}\right) \mathrm{f}=\mathrm{A}_{\mathrm{i}}\left(t_{3}\right) \mathrm{Q}\left(t_{3}\right) \mathrm{f},
$$

For all $\mathrm{f} \in \cap_{i=1}^{r} \quad \mathrm{~A}_{i}, t_{1}, t_{3} \in \mathrm{J}$.

Theorem 2.3. Under all the previous conditions, there exists a dense set $\mathrm{S}$ in $\mathrm{E}$, such that if $\mathrm{f}(\mathrm{t}) \in \mathrm{S}$, for all $\mathrm{t} \in \mathrm{J}$, then equation (1.1) can be solved. Moreover, this solution in unique and continuously depending on $\mathrm{f}$.

Proof: Let $S$ be the set of all elements, of the form $f_{n}(t)=Q\left(\frac{1}{n}\right) \mathrm{f}(\mathrm{t}), \mathrm{n}=1,2, \ldots \ldots, \mathrm{f}(\mathrm{t}) \in \mathrm{E}, \mathrm{t} \in \mathrm{J}$. It is clear that $\mathrm{S}$ is dense in $\mathrm{E}$. According to theorem 2.1, there exists for every $n$ a unique continuous solution $v_{n}(t)$ of the equation 
$=\tilde{\mathrm{f}}\left(\mathrm{t}, \frac{t}{\mathrm{nT}}\right)+\int_{0}^{t} \sum_{i=1}^{r} K_{i}(\mathrm{t}, \theta) A_{i}(\theta) \tilde{v}\left(\theta, \frac{t}{\mathrm{nT}}-\frac{\Theta}{\mathrm{nT}}\right) \mathrm{d} \theta$

Set $\mathrm{u}_{\mathrm{n}}(\mathrm{t})=\mathrm{Q}\left(\frac{1}{\mathrm{n}}-\frac{\mathrm{t}}{\mathrm{nT}}\right) v_{\mathrm{n}}(\mathrm{t})$ and using conditions (2.4)

and (2.5), we find that for every $n, u_{n}(t)$ satisfies the equation

$$
u_{n}(t)=\mathrm{Q}\left(\frac{1}{n}\right) f+\int_{0}^{t} \sum_{i=1}^{r} K_{i}(\mathrm{t}, \theta) A_{i}(\theta) u_{n}(\theta) \mathrm{d} \theta
$$

Notice that according to theorem (2.2), $\mathrm{u}_{\mathrm{n}}(\mathrm{t})$ depends continuously on $\mathrm{f}(\mathrm{t})$.

As a direct application, we consider the following abstract Hilfer fractional integral equation:

$$
\mathrm{u}(\mathrm{t})=\mathrm{f}(\mathrm{t})+\frac{1}{\Gamma(\alpha)} \int_{0}^{t}(\mathrm{t}-\theta)^{\alpha-1} \mathrm{~A}_{1}(\theta) \mathrm{u}(\theta) \mathrm{d} \theta,
$$

where;

$$
\begin{aligned}
\mathrm{f}(\mathrm{t})= & \frac{t^{(\gamma-1)(\alpha-1)}}{\Gamma(\gamma(1-\alpha)+\alpha)} \mathrm{g}, \mathrm{g} \in \mathrm{E}, \\
& 0<\alpha \leq 1,0<\gamma \leq 1 .
\end{aligned}
$$

Equation (2.6) can be solved if we replace $\mathrm{g}$ by $\mathrm{Q}\left(\frac{1}{n}\right) \mathrm{g}$.

\section{Singular Integro-differential Equations}

Consider the following equation $\mathrm{u}(\mathrm{x}, \mathrm{t})=\mathrm{f}(\mathrm{x}, \mathrm{t})+$

$\int_{0}^{t} \sum_{i=1}^{r} \sum_{|q| \leq m} \quad K_{i}(\mathrm{t}, \theta) a_{i q}(\theta) D^{q} \mathrm{u}(\mathrm{x}, \theta) \mathrm{d} \theta$

where; $\mathrm{x}=\left(\mathrm{x}_{1}, \ldots, \mathrm{x}_{\mathrm{k}}\right) \in \mathrm{R}^{\mathrm{k}}, \mathrm{R}^{\mathrm{k}}$ is the $\mathrm{k}$-dimensional Euclidean space,

$\mathrm{q}=\left(q_{1}, \ldots, \mathrm{q}_{\mathrm{k}}\right)$ is a multi-index, $|\mathrm{q}|=\mathrm{q}_{1}+\ldots .+\mathrm{q}_{\mathrm{k}}$,

$\mathrm{D}^{\mathrm{q}}=D_{1}^{q_{1}} \ldots . . D_{k}^{q_{k}}, \mathrm{D}_{\mathrm{j}}=\frac{\partial}{\partial x_{j}}, \quad \mathrm{j}=1, \ldots ., \mathrm{k}$.

The coefficients $a_{1 q}, \ldots . a_{r q}$ are real continuous functions on $\mathrm{J}$, for all $|q| \leq \mathrm{m}$.

For $\mathrm{t}>\theta$, the kernels $\mathrm{K}_{1}(\mathrm{t}, \theta), \ldots, \mathrm{K}_{\mathrm{r}}(\mathrm{t}, \theta)$ are real continuous functions such that;

$$
\left|K_{i}(\mathrm{t}, \theta)\right| \leq \frac{M}{(\mathrm{t}-\theta)^{1-\alpha}},
$$

$\mathrm{M}$ is a positive constant, $0<\alpha \leq 1, \mathrm{t}>\theta, \mathrm{t}, \theta \in \mathrm{J}$.

Let $\mathrm{C}^{\mathrm{m}}\left(\mathrm{R}^{\mathrm{k}}\right)$ be the set of all real continuous functions on $\mathrm{R}^{\mathrm{k}}$, which have continuous derivatives of order less than or equal to $\mathrm{m}$.

Let $\mathrm{W}^{\mathrm{m}}\left(\mathrm{R}^{\mathrm{k}}\right)$ be the completion of $\mathrm{C}^{\mathrm{m}}\left(\mathrm{R}^{\mathrm{k}}\right)$ with respect to the norm:

$$
\|g\|_{m}^{2}=\sum_{|q| \leq \mathrm{m}} \quad \int_{R^{k}}\left|D^{q} \mathrm{~g}(x)\right|^{2} \mathrm{dx} .
$$

Let $\mathrm{E}=\mathrm{L}_{2}\left(\mathrm{R}^{\mathrm{k}}\right)$ be the space of all square integral functions on $\mathrm{R}^{\mathrm{k}}$

It is assumed that $\mathrm{f}$ is a real function defined on $\mathrm{R}^{\mathrm{k}}$ such that for every $\mathrm{t} \in \mathrm{J}, \mathrm{f} \in \mathrm{L}_{2}\left(\mathrm{R}^{\mathrm{k}}\right)$.

In this case we can choose the operator B by

$$
\mathrm{B}=\left[\frac{\partial^{2}}{\partial \mathrm{x}_{1}^{2}}+\ldots+\frac{\partial^{2}}{\partial x_{k}^{2}}\right]^{2 N+1}
$$

The strongly continuous semi group $\mathrm{Q}(\mathrm{t})$ with the infinitesimal generator $\mathrm{B}$ is given by

$$
(\mathrm{Q}(\mathrm{t}) \varphi)(\mathrm{x})=\int_{R^{k}} G(\mathrm{x}-\mathrm{y}, \mathrm{t}) \phi(y) d y,
$$

Where; $G$ is the fundamental solution of the following equation

$$
\frac{\partial \mathrm{u}(\mathrm{x}, \mathrm{t})}{\partial \mathrm{t}}=\left[\frac{\partial^{2}}{\partial \mathrm{x}_{1}^{2}}+\ldots+\frac{\partial^{2}}{\partial x_{k}^{2}}\right]^{2 N+1} \mathrm{u}(\mathrm{x}, \mathrm{t})
$$

For sufficiently large $\mathrm{N}$, we can find constants $\mathrm{M}>0$, $\gamma>0,0<\gamma<\alpha$, such that

$$
\begin{gathered}
\left\|D^{q} \mathrm{Q}(t) \phi\right\| \leq \frac{M}{t^{\gamma}}\|\phi\|, \\
|q| \leq \mathrm{m},
\end{gathered}
$$

Where $\|\cdot\|$ is the norm in $\mathrm{L}_{2}\left(\mathrm{R}^{\mathrm{k}}\right)$,

$$
\|\phi\|^{2}=\int_{R^{k}} \phi^{2}(x) \mathrm{dx} .
$$

The domain of definitions of the operators $\mathrm{A}_{\mathrm{i}}(\mathrm{t})=$ $\sum_{|q| \leq m} a_{q_{i}}(t) \mathrm{D}^{q}$ and $\mathrm{B}$ are $\mathrm{W}^{\mathrm{m}}\left(\mathrm{R}^{\mathrm{k}}\right)$ and $\mathrm{W}^{\mathrm{N}+2}\left(\mathrm{R}^{\mathrm{k}}\right)$ respectively.

These domains of definitions are dense in $\mathrm{L}_{2}\left(\mathrm{R}^{\mathrm{k}}\right)$ and the operators $A_{i}(t)$ and $B$ are closed in $L_{2}\left(R^{k}\right)$.

It is clear that the operators $A_{1}(\theta), . ., A_{r}(\theta)$ are commute with $\mathrm{Q}(\mathrm{t})$, for all $\mathrm{t}, \theta \in \mathrm{J}$.

The given function $f$ as a function of $t$ with values in $L_{2}$ $\left(\mathrm{R}^{\mathrm{k}}\right)$ is supposed to be continuous in $\mathrm{t} \in \mathrm{J}$ with respect to the norm in $\mathrm{L}_{2}\left(\mathrm{R}^{\mathrm{k}}\right)$.

Now all the conditions of section 2 are satisfied.

As in theorem (2.1), we solve in $\mathrm{L}_{2}\left(\mathrm{R}^{\mathrm{k}}\right)$ the following equation:

$$
\begin{gathered}
v_{n}(x, t)=\tilde{\mathrm{f}}(\mathrm{x}, \mathrm{t}, \mathrm{ct})+ \\
\int_{0}^{t} \sum_{i=1}^{r} \sum_{|q| \leq m} \quad K_{i}(\mathrm{t}, \theta) \mathrm{D}^{q} \tilde{v}_{n}(\theta, \mathrm{ct}-\mathrm{c} \theta) \mathrm{d} \theta,
\end{gathered}
$$

Where; $\mathrm{c}=\frac{1}{\mathrm{nT}}$, we find that for every $\mathrm{n}, \mathrm{u}_{\mathrm{n}}=\mathrm{Q}\left(\frac{1}{n}-\frac{1}{\mathrm{nT}}\right)$ $v_{\mathrm{n}}$, solves the equation

$$
\begin{gathered}
\mathrm{u}_{\mathrm{n}}(\mathrm{x}, \mathrm{t})=\mathrm{f}_{\mathrm{n}}(\mathrm{x}, \mathrm{t})+ \\
\int_{0}^{t} \sum_{i=1}^{r} \quad \sum_{|q| \leq m} \quad K_{i}(\mathrm{t}, \theta) \mathrm{a}_{\mathrm{iq}}(\theta) \mathrm{D}^{q} u_{n}(\mathrm{x}, \theta) \mathrm{d} \theta
\end{gathered}
$$

Where;

$$
\mathrm{f}_{\mathrm{n}}(\mathrm{x}, \mathrm{t})=\int_{R^{k}} G\left(\mathrm{x}-\mathrm{y}, \frac{1}{n}\right) \mathrm{f}(\mathrm{y}, \mathrm{t}) \mathrm{dy}
$$

As a special case, we can solve the following Hilfer fractional integro-partial differential equation

$\frac{1}{\Gamma(\alpha)} \int_{0}^{t}(\mathrm{t}-\theta)^{\alpha-1} \sum_{|q| \leq m} a_{q}(\theta) \mathrm{D}^{q} u_{n}(x, \theta) \mathrm{d} \theta$,

$$
\mathrm{u}_{\mathrm{n}}(\mathrm{x}, \mathrm{t})=\mathrm{f}_{\mathrm{n}}(\mathrm{x}, \mathrm{t})+
$$

where;

$$
\mathrm{f}_{\mathrm{n}}(\mathrm{x}, \mathrm{t})=\frac{t^{(\gamma-1)(\alpha-1)}}{\Gamma(\gamma(1-\alpha)+\alpha)} \mathrm{g}_{\mathrm{n}}(\mathrm{x}),
$$




$$
\begin{gathered}
0<\gamma \leq 1, \quad 0<\alpha \leq 1, \\
\mathrm{~g}_{\mathrm{n}}(\mathrm{x})=\int_{R^{k}} G\left(\mathrm{x}-\mathrm{y}, \frac{1}{n}\right) \mathrm{g}(y) \mathrm{dy}, \mathrm{g} \in \mathrm{L}_{2}\left(R^{k}\right),
\end{gathered}
$$

Notice that the solution of (3.1) or (3.2) are elements of $\mathrm{W}^{4 \mathrm{~N}+2}\left(\mathrm{R}^{\mathrm{k}}\right)$, for every $\mathrm{n}$ and every

$$
\mathrm{t}<\mathrm{T} \text {. see [4,6,7-18]. }
$$

Notice also that equations (3.1) and (3.4) are solved without any restrictions on the characteristic forms of the principle parts of the partial operators

Let us study the following equation:

$\mathrm{u}(\mathrm{x}, \mathrm{t})=\mathrm{f}(\mathrm{x}, \mathrm{t})+\int_{0}^{t} K(\mathrm{t}, \theta) \sum_{|q| \leq 2 m} a_{q}(x) \mathrm{D}^{q} \mathrm{u}(\mathrm{x}, \theta) \mathrm{d} \theta$,

where; $\mathrm{K}$ is continuous for $\mathrm{t}>\theta$ and satisfies condition (3.2) and $\mathrm{f}$ satisfies the conditions as in theorem (3.1).

let $\mathrm{B}$ be the operator defined by:

$$
\mathrm{B}=\mathrm{A}^{2 \mathrm{~N}+1} \text {, }
$$

where;

$$
\mathrm{A}=\sum_{|q| \leq 2 m} a_{q}(x) \mathrm{D}^{q},
$$

Let us suppose some regularity conditions on $\mathrm{a}_{\mathrm{k}} ; \mathrm{D}^{\mathrm{q}} \mathrm{a}_{\mathrm{q}} \in$ $\mathrm{C}_{\mathrm{b}}\left(\mathrm{R}^{\mathrm{k}}\right),|\mathrm{q}| \leq \mathrm{N}^{*}$, for sufficiently large $\mathrm{N}^{*}, \mathrm{~N}^{*}>2 \mathrm{~m}$ $(2 \mathrm{~N}+1)$,

where;

$\mathrm{C}_{\mathrm{b}}\left(\mathrm{R}^{\mathrm{k}}\right)$ is the set of all continuous bounded functions on $\mathrm{R}^{\mathrm{k}}$.

Let us suppose also that

$$
(-1)^{\mathrm{m}+1} \sum_{|q|=2 m} a_{q}(x) \mathrm{y}^{q} \geq \mathrm{M}|y|^{2 m},
$$

For all $\mathrm{x} \in \mathrm{R}^{\mathrm{k}}$, where $\mathrm{M}$ is a positive constant, $|y|^{2}=y_{1}^{2}+\ldots .+y_{k}^{2}$

The operators $\mathrm{A}$ and $\mathrm{B}$ are closed operators in $\mathrm{L}_{2}\left(\mathrm{R}^{\mathrm{k}}\right)$ with domain of definitions $\mathrm{W}^{2 \mathrm{~m}}\left(\mathrm{R}^{\mathrm{k}}\right)$ and $\mathrm{W}^{2 \mathrm{~m}(2 \mathrm{~N}+1)}\left(\mathrm{R}^{\mathrm{k}}\right)$ respectively.

The operator $B=A^{2 N+1}$ is the infinitesimal semi-group $\mathrm{Q}(\mathrm{t})$ defined by

$$
(\mathrm{Q}(\mathrm{t}) \varphi)(\mathrm{x})=\int_{R^{k}} G(\mathrm{x}-\mathrm{y}, \mathrm{t}) \phi(y) \mathrm{dy},
$$

Where $\mathrm{G}$ is the fundamental solution of the equation

$$
\frac{\partial \mathrm{u}(\mathrm{x}, \mathrm{t})}{\partial \mathrm{t}}=\left[\sum_{|q|=2 m} a_{q}(x) \mathrm{D}^{q}\right]^{2 N+1} \mathrm{u}(\mathrm{x}, \mathrm{t})
$$

According to the properties of the fundamental solution $\mathrm{G}$, we deduce that the operator $\mathrm{Q}$ satisfies condition (3.3), (see [19-22])

Lemma 3.1 let $f \in W^{2 m}\left(R^{k}\right)$, Then A Q (t) $f=Q$ (t) A f, for all $\mathrm{t} \in \mathrm{J}$.

Proof: It is easy to see that $A_{\mu} B_{\lambda} f=B_{\lambda} A_{\mu} f$,

Where $A_{\mu}$ and $B_{\lambda}$ are the linear bounded operators

$$
\mathrm{A}_{\mu}=-\mu\left[\mathrm{I}-\mu(\mathrm{I} \mu-\mathrm{A})^{-1}\right],
$$

$$
\left.\mathrm{B}_{\lambda}=-\lambda\left[\mathrm{I}-\lambda(\mathrm{I} \lambda-\mathrm{B})^{-1}\right)\right]
$$

Thus;

$$
\operatorname{Lim}_{\mu \rightarrow \infty} A_{\mu} B_{\lambda} f=A B_{\lambda} f=\operatorname{Lin}_{\mu \rightarrow \infty} B_{\lambda} A_{\mu} f=B_{\lambda} A f .
$$

Thus;

$$
\mathrm{A} \mathrm{e}^{\mathrm{t} \mathrm{B} \lambda} f=\mathrm{e}^{\mathrm{t} \mathrm{B} \lambda} A f
$$

Now $\operatorname{Lin}_{\lambda \rightarrow \infty} \mathrm{e}^{\mathrm{tB} \lambda} f=\mathrm{Q}(t) \mathrm{f}$,

And $\operatorname{Lin}_{\lambda \rightarrow \infty} \mathrm{Ae}^{\mathrm{tB}} \lambda f=\mathrm{Q}(t) \mathrm{Af}$,

But $\mathrm{A}$ is closed, thus

$$
A Q(t) f=Q(t) A f
$$

Notice that equation (3.5) is still ill-posed, but we can now solve the following equation:

$$
\mathrm{u}_{\mathrm{n}}(\mathrm{x}, \mathrm{t})=\mathrm{f}_{\mathrm{n}}(\mathrm{x}, \mathrm{t})+\int_{0}^{t} K(\mathrm{t}, \theta) \sum a_{q}(x) \mathrm{D}^{q} \mathrm{u}_{n}(\mathrm{x}, \theta) \mathrm{d} \theta,
$$

where;

$$
\begin{gathered}
\mathrm{f}_{\mathrm{n}}(\mathrm{x}, \mathrm{t})=\int_{R^{k}} G\left(\mathrm{x}, \mathrm{y}, \frac{1}{n}\right) \mathrm{f}(\mathrm{y}, \mathrm{t}) \mathrm{dy}, \\
\mathrm{u}_{\mathrm{n}}(\mathrm{x}, \mathrm{t})=\int_{R^{k}} G\left(\mathrm{x}, \mathrm{y}, \frac{1}{n}-\frac{t}{n T}\right) \mathrm{v}_{n}(\mathrm{y}, \mathrm{t}) d \mathrm{y},
\end{gathered}
$$

$\mathrm{u}_{\mathrm{n}} \in \mathrm{W}^{2 \mathrm{~m}(2 \mathrm{~N}+1)}\left(\mathrm{R}^{\mathrm{k}}\right)$, for every $\mathrm{t} \in \mathrm{J}$ and every $\mathrm{n}=1,2, \ldots$

$\left(v_{\mathrm{n}}\right.$ will be determined as in theorem (2.2)).

\section{Nonlinear Equations}

The results in sections 2 and 3 are obtained after suitable modification on the given function $\mathrm{f}$, which plays in some special cases the role of initial condition.

For the non-linear equation (1.2), we can obtain solutions with stability properties, without conditions (2.4) and (2.5), but after suitable modifications on $\mathrm{f}$ and $\mathrm{F}$. see [23-37].

Let us consider in the Banach space E, the following equation;

$$
v(\mathrm{t})=\mathrm{Q}(\mathrm{ct}) \mathrm{f}(\mathrm{t})+\mathrm{Q}(\mathrm{ct}) \int_{0}^{t} \mathrm{~F}\left(V^{*}(\mathrm{t}, \theta) \mathrm{d} \theta,\right.
$$

where

$$
\begin{gathered}
\mathrm{V}^{*}(\mathrm{t}, \theta)=\left(\mathrm{K}_{1}(\mathrm{t}, \theta) \mathrm{A}_{1}(\theta) \widetilde{\mathrm{V}}\left(\theta, \mathrm{c}-\frac{c \theta}{T}\right), \ldots \mathrm{K}_{\mathrm{r}}(\mathrm{t}, \theta) \mathrm{A}_{\mathrm{r}}(\theta)\right. \\
\tilde{\mathrm{V}}\left(\theta, \mathrm{c}-\frac{c \theta}{T}\right),
\end{gathered}
$$

Where $c>0$,

$\mathrm{V}^{*}(\mathrm{t}, \theta)=\left(\mathrm{K}_{1}(\mathrm{t}, \theta) \mathrm{A}_{1}(\theta) \tilde{\mathrm{V}}\left(\theta, \mathrm{c}-\frac{c \theta}{T}\right)=\mathrm{Q}\left(\mathrm{c}-\frac{c \theta}{T}\right) \vee(\theta)\right.$.

Theorem 4.1 under the conditions on f, F, Q, $\mathrm{K}_{\mathrm{i}}, \mathrm{A}_{\mathrm{i}}$ of sections 1 and 2, (but without conditions (2.4) and (2.5)), there exists a unique solution $v(t) \in E$ of equation (4.1). This solution is continuous in $t \in J$ and is continuously depending on $\mathrm{f}$, (with respect to the norm in $\mathrm{E}$ ).

Proof: Using condition (1.4), we find that the proof is similar to the proof in theorems (2.1) and (2.2).

Let $\mathrm{c}=\frac{1}{n}, \quad \mathrm{u}_{\mathrm{n}}(\mathrm{t})=\mathrm{Q}\left(\mathrm{c}-\frac{c t}{T}\right) \mathrm{v}_{\mathrm{n}}(\mathrm{t})$, where; $\mathrm{v}_{\mathrm{n}}(\mathrm{t})$ is the 
solution of (4.1) with $\mathrm{c}=\frac{1}{n}, \quad 0<\mathrm{t}<\mathrm{T}$.

It is clear that for every $n, u_{n}(t)$ satisfies the following equation, (without conditions (2.4) and (2.5)),

$$
\mathrm{u}_{\mathrm{n}}(\mathrm{t})=\mathrm{f}_{\mathrm{n}}(\mathrm{t})+\int_{0}^{t} F_{n}\left(U_{n}(\mathrm{t}, \theta)\right) \mathrm{d} \theta,
$$

Where;

$$
\begin{gathered}
U_{n}(t, \theta)=\left(K_{1}(t, \theta) A_{1}(\theta) u_{n}(\theta), \ldots ., K_{r}(t, \theta) A_{r}(\theta) u_{n}(\theta)\right), \\
f_{n}=Q\left(\frac{1}{n}\right) f, \quad F_{n}=Q\left(\frac{1}{n}\right)
\end{gathered}
$$

As an application, we can study the following equation in the space $\mathrm{L}^{2}\left(\mathrm{R}^{\mathrm{k}}\right)$;

$$
\mathrm{u}(\mathrm{x}, \mathrm{t})=\mathrm{f}(\mathrm{x}, \mathrm{t})+\int_{0}^{t} \mathrm{~F}(\mathrm{~V}(\mathrm{x}, \mathrm{t}, \theta)) \mathrm{d} \theta,
$$

Where of satisfies the conditions in section 3 and $\mathrm{V}$ is the following:

$\mathrm{V}(\mathrm{x}, \mathrm{t}, \theta)=\left(\mathrm{K}_{1}(\mathrm{t}, \theta) \mathrm{A}_{1}(\theta) \mathrm{u}(\theta), \ldots ., \mathrm{K}_{\mathrm{r}}(\mathrm{t}, \theta) \mathrm{A}_{\mathrm{r}}(\theta) \mathrm{u}(\theta)\right)$,

$\mathrm{K}_{1}, \ldots, \mathrm{K}_{\mathrm{r}}$ are real functions and satisfies the conditions in section 3 .

The operators $A_{1}, \ldots, A_{r}$ are

$$
\begin{gathered}
\mathrm{A}_{\mathrm{i}}(\theta)=\sum_{|q| \leq m} a_{q i}(\mathrm{x}, \theta) \mathrm{D}^{q}, \quad \mathrm{i}=1, \ldots ., \mathrm{r} \\
\mathrm{a}_{\mathrm{qi}} \in \mathrm{C}_{\mathrm{b}}\left(\mathrm{R}^{\mathrm{k}} \times \mathrm{J}\right),|\mathrm{q}| \leq \mathrm{m},
\end{gathered}
$$

In this case, we can use the strongly continuous semi-group $\mathrm{Q}(\mathrm{t})$ with the infinitesimal generator

$$
\mathrm{B}=\left(\frac{\partial^{2}}{\partial x_{1}^{2}}+\ldots . .+\frac{\partial^{2}}{\partial x_{k}^{2}}\right)^{2 N+1}
$$

The well posed version of equation (4.2) is given by:

$\mathrm{u}_{\mathrm{n}}(\mathrm{x}, \mathrm{t})=\mathrm{f}_{\mathrm{n}}(\mathrm{x}, \mathrm{t})+\int_{0}^{t} \mathrm{Fn}\left(V_{n}(\mathrm{x}, \mathrm{t}, \theta)\right) \mathrm{d} \theta$,

Where; $\mathrm{f}_{\mathrm{n}}(\mathrm{x}, \mathrm{t}) \int \mathrm{Q}\left(x-\mathrm{y}, \frac{1}{n}\right) f(\mathrm{y}, \mathrm{t}) \mathrm{dy}$

\section{Conclusions}

A general singular integral evaluation equation is studied in Banach space. The abstract parabolic transform is constructed to investigate a wide class of ill-posed problems. The Hilfer fractional integro-partial differential equations are studied without any restrictions on the characteristic forms.

\section{Acknowledgements}

The authors would like to express their sincere gratitude to the editor-in- chief and the anonymous referees for their valuable comments and suggestions.

\section{REFERENCES}

[1] Levine H A., Some non-existence and instability theorems for formally parabolic equation, Arch. Rat. Mech. Anal., 51 91973), $371-386$.

[2] Levine, H A., Nonexistence of global weak solutions to some property and improperly posed problems of mathematical physics, the method of unbounded Fourier coefficients. Math. Anal., 214 (1975), 205 - 220.

[3] Wvs. M. \& Wvss W., Evolution, its fractional extension and generalization, AR xiv, math., ph/9912023 V1 29 Dec 1999.

[4] Pavane L.E., Improperly posed problems in partial differential equations. SIAM. Philadelphia P., 1975.

[5] Schneider W R, Ways W., Fractional diffusion and wave equation, J. Math. Phys. (1989). 30-34.

[6] Ways W., The fractional diffusion equation, Math. Phys., (1986), 27-50.

[7] Goren Flo R., Mainardi F., Fractional calculus and stable probability distributions. Arch. Mech., 50 (1995), 377-388.

[8] El-Borai M.M., On the correct formulation of the Cauchy problem and the mixed problem for a self-conjugate equation, Vestnik Moscow univ. Ser. 1 Math., 20 (1967), no. $3,12-21$.

[9] El-Borai M.M., On the correct formulation of the Cauchy problem. Vestnik Moscow univ. Ser. 1 Math. Mech., 23 91968), no. 4, 16-24.

[10] El-Borai M.M., Some probability densities and fundamental solutions of fractional evolution equation, Chaos, Solitons and Fractals, 14 (2002), 433-440.

[11] El-Borai M.M. Evolution equations without semi-groups. Applied Mathematics and Computations, 149 (2004), no. 3. 815-821.

[12] El-Borai M.M. Semigroups and some nonlinear fructional differential equations. Applied Mathematics and Computation. 149 (2004), no. 3. 823 - 831.

[13] Eidelman S.D., Fundamental solutions of parabolic systems, Mat. Sb. (NS), 1956, Volume 38 (80) No. 1, 51-92.

[14] El-Borai M. Mahmoud, A parabolic transform and some stochastic ill-posed problems, British Journal of Mathematics and Computer Science, 9(45), 2015, Article no. BJMCS. 2015. 213, 418 - 426.

[15] Ai-lin Qian. Spectral method and its application to a Cauchy problem of the Laplace equation. IJRRAS. 2013: 14(1): 51-57.

[16] Xiong T. Central difference regularization method for the Cauchy problem of Laplace's equation. Allied Mathematics and Computation. 2006: 18: 675 - 684 . 
[17] Krylov N N, Rogovskii BL. On the Cauchy problem for linear stochastic partial differential equations. Izv, Akad. SSS R. 1977; 41: 1267-1284.

[18] Mahmoud M. El-Borai. Generalized random processes and Cauchy's problem for some partial differential equations. Int. J. of Math. And mathematical Sc. No. 3. 1980; 549 - 558.

[19] Mahmoud M. El-Borai, Khairia El-Said El-Nadi, Osama L. Mostafa, M. Hamdy. Volterra equations with fractional stochastic integrals. Mathematical Problems in Engineering. $2004 ; 5: 453-468$

[20] Mahmoud M. El-Borai, Khairia El-Said El-Nadi, Osama L. Mostafa, M. Hamdy. Numerical method for some nonlinear stochastic differential equations. Applied Math. and Comp. 2005; 168: 65-75.

[21] Mahmoud M. El-Borai. On some fractional differential equations in the Hilbert space. Journal of Discrete and Continuous Dynamical Systems, Series A. 2005; 233-241.

[22] Mahmoud M. El-Borai. On some stochastic integro-differential equations. Advances in Dynamical Systems and Applications 2006; 1(1): 49-57.

[23] Mahmoud M. El-Borai, Khairia El-Said El-Nadi, Iman G. El-Akabawy. Approximate solutions for nonlinear fractional heat equations. Int. J. Contemp. Math. Sciences. 2007; 2(27): 1307-1316.

[24] Mahmoud M. El-Borai, Khairia El-Said El-Nadi, Osama L. Mostafa, Hamdy M. Ahmed. Semi group and some fractional stochastic integral equations. Int. J. of Pure and Applied Mathematical Sciences. 2006; 3(1): 47-52.

[25] Mahmoud M. el-Borai, Khairia El-Said El-Nadi, hoda A. Foad. On some fractional stochastic delay differential equations. Computers and mathematics with Applications. 2010; 59: 1165-1170.

[26] Mahmoud M. El-Borai, Khairia El-Said El-Nadi. Eman G. El-Akabawy. On some fractional evolution equations. Computers and mathematics with Applications. 2010; 59: 1352-1355.

[27] Khairia El-Said El-Nadi. On some stochastic parabolic differential equations in a Hilbert space journal of Applied Mathematics and Stochastic Analysis. 2005; (2): 167-175.

[28] Khairia El-Said El-Nadi. On some stochastic differential equations and fractional Brownian motion. International Journal of Pure and Applied Mathematics. 2005; 24(3): 416-423.

[29] Khairia El-Said El-Nadi. On the stability of some stochastic integro partial differential equations. Int. J. Contemp. Math. Sciences. 2007; 2(27): 1317-1326.

[30] Kairia El-Said El-Nadi, Mahmoud M. El-Borai. Integrated Semi groups and Cauchy problem for some fractional abstract differential equations. Life Science Journal. 2013; 10(3): 793-798.

[31] Kairia El-Said El-Nadi, Mahmoud M. El-Borai. An inverse fractional abstract Cauchy problem with nonlocal conditions. Life Science Journal. 2013; 10(3): 1705-1709.

[32] Ahmed, H. M., and El-Borai, M. M. Hilfer fractional stochastic integro-differential equations. Applied Mathematics and Computation 331 (2018); 182-189.
[33] El-Borai, M. M. the fundamental solutions for fractional evolution equations of parabolic type. International Journal of Stochastic Analysis 2004; 3(2004), 197-211.

[34] El-Borai, M. M. On some fractional differential equations in the hilbert space. Journal of Discrete and Continuous Dynamical Systems, Series A (2005); 233-241.

[35] El-Borai, M. M. On some stochastic fractional integro-differential equations. Advances in Dynamical Systems and Applications 1, 1 (2006); 49-57.

[36] El-Borai, M. M., and El-Nadi, K. E. S. Integrated semi groups and Cauchy problem for some fractional abstract differential equations. Life Science Journal 10, 3(2013); 793-795.

[37] El-Borai, M. M., El-Nadi, K. E. S., Ahmed, H. M., El-Owaidy, H. M., Ghanem, A. S., and Sakthivel, R. Existence and stability for fractional parabolic integro-partial differential equations with fractional Brownian motion and nonlocal condition. Cogent Mathematics \& Statistics 5, 1 (2018), 146-166. 